\title{
Social Support, Self-Regulation, and Psychological Skill Use in E-Athletes
}

\author{
Michael G. Trotter ${ }^{1}$, Tristan J. Coulter ${ }^{1}$, Paul A. Davis ${ }^{2 *}$, Dylan R. Poulus ${ }^{3}$ and \\ Remco Polman ${ }^{1}$ \\ ${ }^{1}$ Faculty of Health, School of Exercise and Nutrition Sciences, Queensland University of Technology, Brisbane, QLD, \\ Australia, ${ }^{2}$ Department of Psychology, Umeå University, Umeå, Sweden, ${ }^{3}$ School of Health and Human Sciences, Southern \\ Cross University, Bilinga, QLD, Australia
}

\section{OPEN ACCESS}

Edited by:

Kirill Micallef Stafrace, University of Malta, Malta

Reviewed by:

Giulia Casu,

University of Bologna, Italy Phillip G. Post,

New Mexico State University, United States

*Correspondence: Paul A. Davis paul.davis@umu.se

Specialty section: This article was submitted to Movement Science and Sport

Psychology,

a section of the journal

Frontiers in Psychology

Received: 08 June 2021 Accepted: 06 October 2021 Published: 11 November 2021

Citation: Trotter MG, Coulter TJ, Davis PA, Poulus DR and Polman R (2021) Social Support, Self-Regulation, and Psychological Skill Use in E-Athletes.

Front. Psychol. 12:722030. doi: 10.3389/fpsyg.2021.722030
The aims of the present study were twofold. First, to investigate self-reported social support, self-regulation, and psychological skill use in esports athletes (e-athletes) compared to traditional athletes. Second, to determine if self-reported social support, self-regulation, and psychological skill use influenced e-athlete in-game rank. An online survey was used to collect data from an international sample of e-athletes $(n=1,444)$. The e-athletes reported less social support, self-regulation, and psychological skill use than reported by traditional athletes in previous studies. E-athletes with higher scores in social support, self-regulation, and psychological skill use was associated with higher in-game rank. The lack of an organisational structure in esports may be a contributing factor as to why e-athletes score lower than traditional athletes on social support, self-regulation, and psychological skill use. Future research is warranted to explore the development of esports programs aiming to promote athletes' social support, self-regulation, and use of psychological skills to enhance in-game performance and well-being.

Keywords: esports, video game, competitive video games, cyber sport, e-athlete, self-regulation, social support, psychological skills

\section{INTRODUCTION}

Esports has been defined as "organised video game competitions" (Jenny et al., 2017; p. 4) and has shown a rapid growth in terms of its number of e-athletes and spectators over the last 10 years (Newzoo, 2020), and it is currently valued at well over 24 billion dollars (Ahn et al., 2020). The esports industry is noted to have experienced limited disruption as a result of COVID-19 pandemic, with participation rates continuing to rise (López-Cabarcos et al., 2020). There is increasing research activity examining the health and well-being of e-athletes (e.g., Trotter et al., 2020), as well as the psychological factors which potentially influence esports performance (e.g., Himmelstein et al., 2017; Poulus et al., 2020). However, considering the extent of research examining esports, the current understanding of optimal training and coaching methods involved in optimising esports performance is limited.

Based on the definition of esports above, we define e-athletes as those who play an esport and have an official ranking for that esport. Ranking in esports is like the ELO system in chess, however, has different algorithms for each esport (see Poulus et al., 2020). Obtaining a ranking for most esports indicates that the individual has played a minimum number of games and has past the playing for fun stage and now competes to win. There is a need for further research to examine 
e-athletes' development to facilitate optimal performance and well-being. Although there are many factors which could potentially influence esports performance (e.g., physical fitness, general health, and stress coping; Polman et al., 2018; Poulus et al., 2020; Trotter et al., 2020), this study focuses specifically on psychological factors (i.e., self-regulation, psychological skill use, and social support). Evidence suggests that social support (Freeman and Rees, 2008; Arnold et al., 2018), self-regulation (Jonker et al., 2011), and psychological skill use (Tod et al., 2011; Brown and Fletcher, 2017; Shaari et al., 2019; Röthlin et al., 2020) can directly or indirectly enhance athletic performance. However, the influence of social support, self-regulation, and psychological skill use on e-athletes' performance is still relatively unknown, despite previous research suggesting these factors as an area of future research (Freeman and Wohn, 2017; Himmelstein et al., 2017; Brevers et al., 2020).

Previous research into the psychology of e-athletes can be separated into four categories: stress and coping (Smith et al., 2019; Poulus et al., 2020), psychological skill use (Himmelstein et al., 2017), self-regulation (Brevers et al., 2020), and the comparison of e-athletes with traditional sporting athletes (Kang et al., 2020). For example, research has outlined similarities and differences between e-athletes and traditional athletes in terms of stress and coping response and their psychological profiles (Kang et al., 2020; Poulus et al., 2020). In particular, e-athletes report stressors not previously reported by traditional athletes and appraise these stressors as both a challenge and a threat (Poulus et al., in press). Kang et al. (2020) outlined that, compared to baseball players, e-athletes had higher levels of novelty seeking, self-directedness, and self-transcendence, but lower scores in state anxiety.

Research has previously explored psychological skill use (e.g., goal-setting, imagery, and attentional control; Himmelstein et al., 2017), self-regulation (self-directedness, self-efficacy, and self-control; Kang et al., 2020), and received social support (Freeman and Wohn, 2017) in e-athletes. However, to date, no research exists exploring these factors with e-athletes' ingame rank.

\section{Social Support}

Social support is generally conceptualised as either structural or functional, both of which have been associated with increased sporting performance (Freeman and Rees, 2008). Structural support includes an individual's network and interconnections of social relationships. Research focusing solely on the exclusive impact of structural support is rare (Freeman, 2020). However, increased structural support has been linked to athletes' enhanced stress coping and increased performance (Freeman and Rees, 2008; Arnold et al., 2018). Functional support refers to the resources or actions that can come from four dimensions: emotional, esteem, informational, and tangible (Freeman, 2020). Functional support can be categorised as either perceived or received social support (Freeman, 2020). Perceived support relates to the perception of potential access to social support, and received support refers to specific actions of support by an individual's social networks (Freeman et al., 2011). Evidence shows that received social support positively impacts athletic performance. Freeman and Rees (2008) demonstrated that received social support generated a stress-buffering effect in highperforming golfers. Received social support is also associated with burnout, self-confidence, increased motivation, and performance (Rees et al., 1999; Rees and Freeman, 2007; DeFreese and Smith, 2013; Freeman et al., 2014). To date, there has been no research linking e-athletes' in-game performances to received social support. However, in a qualitative study, Freeman and Wohn (2019) investigated how esports teams are formed and how they coordinate. In particular, the authors noted that social capital was important in the formation and coordination of effective esports teams. In the formation of esports teams, amateur e-athletes reportedly favoured unstructured recruitment methods (e.g., offline social networks, system matchmaking, and social media crowdsourcing), whereas professional e-athletes preferred formal methods of recruiting teammates. Despite our limited understanding of the role of received social support and how social connections influence esports team formation, no research has explored the link between received functional social support and e-athletes in-game rank. We decided to focus on perceived functional support in the present study because it has been shown to be more consistently related to performance (e.g., Freeman and Rees, 2010), the availability of a reliable and valid tool for its measurement, and to make meaningful comparisons with previous sport studies.

\section{Self-Regulation}

Self-regulation has been described as the "self-generated thoughts, feelings, and actions that are planned and cyclically adapted to the attainment of personal goals" (Zimmerman, 2000, p. 14). Self-regulation involves seven stages, namely: informational input, self-evaluation, instigation to change, search, planning, implementation, and plan evaluation (Brown, 1998; Brown et al., 1999). Self-regulation has been shown to predict performance in sport and academia (Jonker et al., 2011). Jonker et al. (2011) reported that participants with greater selfreported self-regulation scores were likely to be more successful in both academia and elite sports. Other studies have provided further support for this finding, showing that highly selfregulated traditional athletes were more likely to be selected for national level teams in football (Erikstad et al., 2018). Selfregulation skills_-such as planning, goal setting, self-monitoring, and reflection-have been described as regular practices used by athletes (Pilgrim et al., 2018).

Self-monitoring and self-reflective skills, associated with the evaluation phase of self-regulation, are noted to be related to higher achievement levels (Jonker et al., 2010; Popa et al., 2020). Traditional athletes, with better self-reflection and selfmonitoring skills, are between 2.75 and 11 times more likely to achieve elite level status in sport (Bartulovic et al., 2017; Te Wierike et al., 2018). No empirical research examining the association between self-regulation and esports currently exists. However, Brevers et al. (2020) suggest that similarities between the rule-based nature of esports and traditional competitive sports justifies the investigation into the association between esports and executive functions, such as self-regulation. Further research examining self-regulation is suggested to benefit 
teachers, athletes, coaches, and parents, who are involved in esports (Brevers et al., 2020).

\section{Psychological Skill Use}

Over the last decade, there has been increasing interest in using sport psychology techniques to maximise competitive sports performance in traditional athletes, through psychological skills training (PST) programs (Meggs and Chen, 2019). PST programs target such skills as goal setting, self-talk, relaxation, imagery, attentional control, emotional control, activation, automaticity, and negative thinking. A reported benefit of psychological skill use is emotional stability (control), which has been shown to account for over $36 \%$ of the variance of stress-coping in gymnasts (Woodman et al., 2010). A recent study of the effectiveness of PST programs on 95 athletes, from a variety of sports (e.g., tennis, curling, floorball, badminton), highlighted that increased use of psychological strategies had a positive influence on performance-related factors, such as emotional and attentional control (Röthlin et al., 2020). Similarly, psychological skill use has been found to be employed by e-athletes in training and competition (Himmelstein et al., 2017). In a qualitative study using interviews to explore the psychological skill use of League of Legends e-athletes $(n=5)$ Himmelstein et al. (2017) identified two higher-order themes related to psychological skill usenamely, techniques used to achieve optimal performance and obstacles encountered by competitive gamers. The psychological skills identified in Himmelstein et al.'s (2017) study were related to the higher-order theme optimal performance (e.g., goal setting, imagery, attentional control). The authors suggested that future PST programs would be beneficial for e-athletes. Currently, there are no studies investigating the psychological skill use of e-athletes using existing quantitative measures, and none that compare e-athletes' use of psychological skills with athletes from traditional sports.

Previous research indicates that social support, selfregulation, and psychological skill use influence traditional sports performance (e.g., Freeman and Rees, 2008; Jonker et al., 2011; Meggs and Chen, 2019). However, there is currently little empirical evidence of these psychological constructs in esports performance research. Therefore, the first aim of this exploratory study was to understand the levels of social support, self-regulation, and psychological skill use that exist in a global esports population and identify how e-athletes compare to traditional athletes on these factors. The second aim was to determine if social support, self-regulation, and psychological skill use are associated with player in-game rank (e.g., achievement level).

\section{MATERIALS AND METHODS}

\section{Participants}

In total, 2,459 adult e-athletes (742 male, 80 female, 29 other; 1,608 not disclosed) started the study survey, of which $58.7 \%$ $(n=1,444)$ completed sufficient and reliable information to be included in the final analysis. E-athletes' responses were included in the study if their responses were not deemed to be spurious, reported their in-game rank for their respective esport, and completed all items of at least one of the instruments measuring either social support, self-regulation, or psychological skill use.

E-athletes reported the esports games they were most highly ranked in. These games included, Overwatch $(n=643)$, League of Legends $(n=410)$, Counter-Strike Global Offensive $(n=193)$, Rocket League $(n=124)$, and Defence Of The Ancients (DOTA) $(n=74)$. Esports have been categorised into three broad categories, First Person Shooters (FPS), Multiplayer Online Battle Arenas (MOBA) and Sports games. All the games in the present study are MOBA, however in Rocket League e-athletes can achieve an online rank in both solo and team matches. Although the games differ in terms of their mechanics all are similar in that they are games of invasion, where the objective is to enter an opponent's territory to achieve objectives such as scoring goals or destroying towers.

The participants ranged across all levels of esports experience and were categorised in line with previous research to allow for comparisons across the different esports (see Trotter et al., 2020). The number of e-athletes in each skill rank group was as follows: $0-69 \%$ skill group $(n=846), 70-79 \%(n=226), 80-89 \%(n=175)$, $90-100 \%(n=197)$. In total 843 e-athletes reported their country of residence. In total 65 countries were reported with the majority being from the United States of America $(n=290,34.4 \%)$, Australia ( $n=18021.4 \%)$ Canada ( $n=75,8.9 \%)$, and Germany $(n=41,4.9 \%)$.

\section{Instruments}

All demographic questions were in the English language. Similarly, the original English versions of the instruments below were used.

\section{Social Support}

Social support was measured using the Athletes Received Support Questionnaire (ARSQ; Freeman et al., 2014). The ARSQ has 22-items and 4 factors: emotional support, esteem support, information support, and tangible support. Emotional support refers to behaviours related to comfort, security, and being cared for (e.g., In the last week, how often did someone cheer you up?). Esteem support involves activities which support or bolster a person's self-esteem (e.g., In the last week, how often did someone encourage you?). Informational support is considered to include advice and guidance (e.g., In the last week, how often did someone give you advice about performing in competitive situations?). Tangible support is defined as practical and instrumental assistance (e.g., How often, in the last week, did someone help plan your training). The ARSQ is scored on a 5 -point Likert scale with $1=$ Not at all, $2=$ once or twice, $3=$ three or four times, $4=$ five or six times, and $5=$ seven or more times. Freeman et al. (2014) have provided evidence for the factorial structure, convergent validity, and reliability of the ARSQ with athletes competing mainly in British Universities and College sport competitions as well as a sample of competitive athletes across multiple sports. The reliability of the factors of the ARSQ was good for the present study (emotional support $\alpha=0.83$; esteem support $\alpha=0.90$; informational support $\alpha=0.89$; tangible support $\alpha=0.84$ ). 


\section{Self-Regulation}

The Self-Regulation Questionnaire (SRQ; Brown et al., 1999) was used to measure self-regulatory skills. The SRQ consists of 63 items and 6 factors, including evaluating (e.g., I think a lot about how I'm doing), triggering (Usually I see the need to change before others do), searching (There is usually more than one way to accomplish something), planning (Once I have a goal, I can usually plan how to reach it), implementing (I have rules that I stick by no matter what), and assessing (I change the way I do things when I see a problem with how things are going). The SRQ is scored on a 5-point Likert scale, ranging from $1=$ strongly disagree to $5=$ strongly agree. Scores for individual factors can be calculated, but an overall SRQ score, using all factors, has been recommended (Brown et al., 1999). Scores for an overall selfregulation score can be classified as high $(>239)$, intermediate (214-238), or low (<213; Brown et al., 1999). The SRQ has good reliability $(\alpha=0.91)$ and validity $(r=0.94, p<0.0001)$ and has been previously used to measure self-regulation in varied sporting populations (Brown et al., 1999; Sadri and Janani, 2015; Shandi et al., 2016; Thapar and Nancy, 2018; Gupta and Sudhesh, 2019). In the present study reliability was moderate to good for five factors and the total scale (receiving $\alpha=0.61$; searching $\alpha=0.67$; planning $\alpha=0.76$; implementing $\alpha=0.73$; assessing $\alpha=0.67$; total scale $\alpha=0.88$ ) but poor for two factors (evaluating $\alpha=0.44$; triggering $\alpha=0.49$ ). Systematic removal of items resulted in removing items 2,30 , and 58 from the evaluation factor and item 59 from the triggering factor (evaluating $\alpha=0.63$; triggering $\alpha=0.60)$.

\section{Psychological Skill Use}

To measure psychological skill use, the Test of Performance Strategies-2 (TOPS-2; Hardy et al., 2010) questionnaire was used. The TOPS-2 has 64 items, with 36-items related to competition and 36-items related to training. In this study, we only used competition-related items. The TOPS-2 consists of nine factors: goal setting, imagery, relaxation, activation, selftalk, emotional control, automaticity, negative thinking, and distractibility. Distractibility was not included in this study, due to previous research reporting low internal consistency (see Hardy et al., 2010). The TOPS-2 is scored on a 5-point Likert scale ranging from $1=$ strongly disagree to $5=$ strongly agree. The TOPS-2 has been shown to have good factorial structure (Hardy et al., 2010). In addition, adequate reliability was reported except for the Distractibility factor. As such this factor was not used in the present study as recommended by Hardy et al. (2010). In the present study Cronbach alpha for the factors of the TOPS2 were adequate to good (self-talk $\alpha=0.70$; emotional control $\alpha=0.81$; automaticity $\alpha=0.60$; goal-setting $\alpha=0.84$; imagery $\alpha=0.79$; activation $\alpha=0.72$; relaxation $\alpha=0.83$; negative thinking $\alpha=0.76)$.

\section{Player Expertise}

Esports games categorise e-athletes into skill groups, which indicate player expertise. Skill groups are categorised by in-game rank, which is determined by factors, such as wins and losses and other in-game statistics. The specific in-game statistics, which influence in-game rank, vary from game-to-game and are often not available to the public. In line with previous research (see Poulus et al., 2020; Trotter et al., 2020), this study measured player expertise using player rank.

\section{Procedure}

This study was approved by the institution of the first authors' research ethics committee (ethics approval number 1800000436). The survey was distributed in two ways: (a) via social media sites, such as Facebook, Twitter, Reddit, and YouTube; and (b) at major esports events in Australia. Prior approval from event organisers was obtained before data collection occurred. Participants who engaged with the social media recruitment strategy were directed to a digital link to the survey, whereas participants collected at esports events completed the survey on an iPad. All participants provided informed consent by agreeing to the survey terms.

\section{Analysis Strategy}

Data were initially screened for outliers and any unrealistic, incomplete, and invalid data were removed leaving 1,444 valid cases. Because of the relatively large sample size, participants who had missing responses for either the ASRQ, SRQ, or TOPS-2 were not included in the analysis for that particular instrument. Normality and homoscedasticity of our dataset was examined. It is well-established that, in large samples $(>40)$, the violation of normality has little influence and parametric statistics can be performed (Ghasemi and Zahediasl, 2012). There was no violation regarding homoscedasticity.

To examine the levels of social support, self-regulation, and psychological skill use in e-athletes, descriptive statistics were computed. In addition, Pearson product moment correlations were calculated between variables, with a small effect $<0.30$, a medium effect $0.31-0.50$, and a large effect $>0.51$ ranges employed (Cohen, 1988). A one sample $t$-test was then run to compare the mean results of previous studies on social support, self-regulation, and psychological skill use, with the results recorded for the different factors of each scale obtained in the present study. Effect size for the one-sample $t$-test was calculated using Cohen's $\mathrm{d}$ with 0.2 being small, 0.5 medium, and 0.8 and above large (Cohen, 1988).

Multivariate analysis of variance (MANOVA) was conducted to examine differences between social support, self-regulation, and psychological skill use with player rank. In the instance of a significant effect, univariate analysis of variance (ANOVA) was conducted and post hoc comparisons were calculated using Sidak. Effect size for the ANOVA was explored using partial eta squared $\left(\eta_{p}^{2}\right)$, with a small effect $0.01-0.059$, medium effect 0.06-0.139, and a large effect $>0.14$ (Cohen, 1988).

\section{RESULTS}

Means and standard deviations for the factors associated with social support, self-regulation, and psychological skill use are reported in Table 1. Table 2 provides information on the number of participants in each skill level category, and Table 3 provides 
TABLE 1 | Means and standard deviation (SD) for received social support, self-regulation, and psychological skills for the sample as a whole and for the different skill categories.

\begin{tabular}{|c|c|c|c|c|c|}
\hline Factor & Mean (SD) & Mean (SD) 0-69\% & Mean (SD) 70-79\% & Mean (SD) 80-89\% & Mean (SD) $90-100 \%$ \\
\hline \multicolumn{6}{|c|}{ Received social support } \\
\hline Emotional support & $1.99(0.98)$ & $1.94(0.94)$ & $2.02(0.94)$ & $2.11(0.91)$ & $2.37(1.02)$ \\
\hline Esteem support & $1.92(0.95)$ & $1.84(0.86)$ & $2.06(1.02)$ & $2.09(0.92)$ & $2.31(1.05)$ \\
\hline Information support & $1.98(0.93)$ & $1.91(0.86)$ & $2.12(0.95)$ & $2.23(0.95)$ & $2.40(1.05)$ \\
\hline Tangible support & $1.36(0.60)$ & $1.32(0.53)$ & $1.38(0.56)$ & $1.37(0.58)$ & $1.62(0.79)$ \\
\hline \multicolumn{6}{|l|}{ Self-regulation } \\
\hline Informational input & $3.66(0.51)$ & $3.63(0.52)$ & $3.65(0.46)$ & $3.75(0.52)$ & $3.81(0.49)$ \\
\hline Evaluating & $3.27(0.46)$ & $3.27(0.48)$ & $3.36(0.42)$ & $3.24(0.47)$ & $3.33(0.44)$ \\
\hline Triggering & $3.48(0.44)$ & $3.44(0.42)$ & $3.52(0.44)$ & $3.56(0.49)$ & $3.50(0.45)$ \\
\hline Searching & $3.76(0.52)$ & $3.72(0.50)$ & $3.77(0.52)$ & $3.74(0.56)$ & $3.93(0.49)$ \\
\hline Planning & $3.20(0.65)$ & $3.15(0.63)$ & $3.21(0.65)$ & $3.25(0.71)$ & $3.37(0.65)$ \\
\hline Implementing & $3.26(0.64)$ & $3.26(0.64)$ & $3.24(0.57)$ & $3.29(0.66)$ & $3.40(0.65)$ \\
\hline Assessing & $3.42(0.48)$ & $3.39(0.48)$ & $3.49(0.43)$ & $3.41(0.45)$ & $3.51(0.48)$ \\
\hline Total self-regulation & $216.45(22.03$ & $214.68(21.13)$ & $218.21(20.48)$ & $218.29(24.14)$ & 223.59 (21.46) \\
\hline \multicolumn{6}{|l|}{ Psychological skills } \\
\hline Self-talk & $2.67(0.92)$ & $2.61(0.87)$ & $2.82(0.97)$ & $2.68(0.86)$ & $2.95(0.98)$ \\
\hline Emotional control & $3.80(0.89)$ & $3.83(0.85)$ & $3.69(0.94)$ & $3.80(0.92)$ & $3.84(0.87)$ \\
\hline Automaticity & $3.41(0.76)$ & $3.28(0.72)$ & $3.53(0.75)$ & $3.53(0.70)$ & $3.75(0.74)$ \\
\hline Goal setting & $2.71(1.05)$ & $2.57(1.03)$ & $2.76(1.05)$ & $2.80(1.02)$ & $3.04(1.01)$ \\
\hline Imagery & $2.64(1.04)$ & 2.55 (1.03) & $2.61(1.05)$ & $2.56(0.95)$ & $3.02(1.03)$ \\
\hline Activation & $3.01(0.84)$ & $2.94(0.81)$ & $3.15(0.81)$ & $2.99(0.80)$ & $3.34(0.78)$ \\
\hline Relaxation & $2.53(1.07)$ & $2.52(1.07)$ & $2.64(1.06)$ & $2.44(1.04)$ & $2.60(1.10)$ \\
\hline Negative thinking & $2.75(0.93)$ & $2.74(0.93)$ & $2.86(0.95)$ & $2.73(0.98$ & $2.64(0.89)$ \\
\hline
\end{tabular}

information on the number of participants in each self-regulation category, based on their total score.

Correlational analysis of the study variables is reported in Table 4. Most correlations were positive in nature and all were small to moderate in magnitude. Only the psychological skill, selftalk, was moderately associated with any of the social support factors. In addition, there were several moderate associations

TABLE 2 | Frequency of esports player in each rank category.

\begin{tabular}{lcc}
\hline Rank & Frequency & Percent \\
\hline $0-69 \%$ & 846 & 58.6 \\
$70-79 \%$ & 226 & 15.7 \\
$80-89 \%$ & 175 & 12.1 \\
$90-100 \%$ & 197 & 13.6 \\
Total & 1,444 & 100 \\
\hline
\end{tabular}

TABLE 3 | Self-regulation classification based on the total score of the SRQ.

\begin{tabular}{lcc}
\hline SR classification & Frequency & Percent \\
\hline Low/impaired & 423 & 42.6 \\
Moderate & 427 & 43.0 \\
High/intact & 143 & 14.4 \\
Total & 993 & 100
\end{tabular}

between the psychological skill use and self-regulatory factors. For example, both searching and assessing was moderately associated with self-talk, goal setting, imagery, and activation; whereas, planning and implementing were moderately positively associated with emotional control and activation, and moderately negatively correlated with negative thinking.

To address our first aim, we compared e-athletes scores on the ARSQ, TOPS-2, and SRQ with studies on traditional athletes which used the same measures. To date, six studies have used the ARSQ. We compared our data with that reported by Hartley and Coffee (2019), because they used the English version of this instrument and collected data from athletes from multiple sports $(n=54)$ with a mean age of 26 years and mixed achievement levels (from recreational to international). Of the four studies that have used the SRQ, we used a study, conducted by Sadri and Janani (2015), on 100 male swimmers with a mean age of 23 and 11 years of experience on average, as it is the only study to report scores for the individual SRQ factors. Finally, for the TOPS-2, we compared our findings with those of Kruk et al. (2017), with male soccer players aged between 16 and 27 years $(M=18.2$ years) from regional clubs with 3-15 years playing experience ( $M=9.33$ years), because it is one of only two studies which used the competition version of the TOPS-2. The other study, meeting this criterion, was deemed unsuitable, because the participants were army recruits (Fitzwater et al., 2018). 
TABLE 4 | Pearson product moment correlations between study variables.

\begin{tabular}{|c|c|c|c|c|c|c|c|c|c|c|c|}
\hline \multirow[b]{2}{*}{ Variable } & \multicolumn{4}{|c|}{ Received social support (ARSQ) } & \multicolumn{7}{|c|}{ Self-regulation (SRQ) } \\
\hline & $\begin{array}{l}\text { Emotional } \\
\text { support }\end{array}$ & $\begin{array}{l}\text { Esteem } \\
\text { support }\end{array}$ & $\begin{array}{c}\text { Info } \\
\text { support }\end{array}$ & $\begin{array}{l}\text { Tangible } \\
\text { support }\end{array}$ & $\begin{array}{c}\text { Informational } \\
\text { input }\end{array}$ & Evaluating & Triggering & Searching & Planning & Implementing & Assessing \\
\hline \multicolumn{12}{|c|}{ Psychological skills (TOPS-2) } \\
\hline Self-talk & 0.30 & 0.35 & 0.31 & 0.32 & 0.21 & 0.13 & 0.17 & 0.37 & 0.22 & 0.22 & 0.30 \\
\hline Emotional control & -0.08 & -0.08 & -0.13 & -0.16 & 0.20 & -0.23 & 0.20 & 0.17 & 0.35 & 0.38 & 0.08 \\
\hline Automaticity & 0.11 & 0.15 & 0.13 & 0.11 & 0.14 & 0.01 & 0.06 & 0.22 & 0.18 & 0.26 & 0.13 \\
\hline Goalsetting & 0.21 & 0.26 & 0.26 & 0.27 & 0.29 & 0.20 & 0.18 & 0.36 & 0.33 & 0.22 & 0.45 \\
\hline Imagery & 0.26 & 0.29 & 0.26 & 0.27 & 0.17 & 0.15 & 0.12 & 0.30 & 0.20 & 0.12 & 0.29 \\
\hline Activation & 0.22 & 0.28 & 0.27 & 0.28 & 0.27 & 0.04 & 0.23 & 0.43 & 0.38 & 0.37 & 0.33 \\
\hline Relaxation & 0.18 & 0.25 & 0.18 & 0.25 & 0.13 & 0.15 & 0.14 & 0.29 & 0.08 & 0.11 & 0.27 \\
\hline Negative thinking & -0.02 & -0.06 & 0.02 & 0.00 & -0.18 & 0.22 & -0.21 & -0.24 & -0.38 & -0.33 & -0.14 \\
\hline \multicolumn{12}{|c|}{ Received social support (ARSQ) } \\
\hline Emotional support & & & & & 0.05 & 0.10 & 0.04 & 0.22 & 0.07 & 0.10 & 0.12 \\
\hline Esteem support & & & & & 0.12 & 0.11 & 0.07 & 0.26 & 0.09 & 0.11 & 0.17 \\
\hline Informational support & & & & & 0.10 & 0.14 & 0.04 & 0.21 & 0.05 & 0.0 & 0.16 \\
\hline Tangible support & & & & & 0.08 & 0.09 & -0.03 & 0.17 & 0.04 & 0.06 & 0.14 \\
\hline
\end{tabular}

TABLE 5 $\mid T$-test comparisons between traditional sports and esports data $\left({ }^{\star \star} P<0.001\right)$.

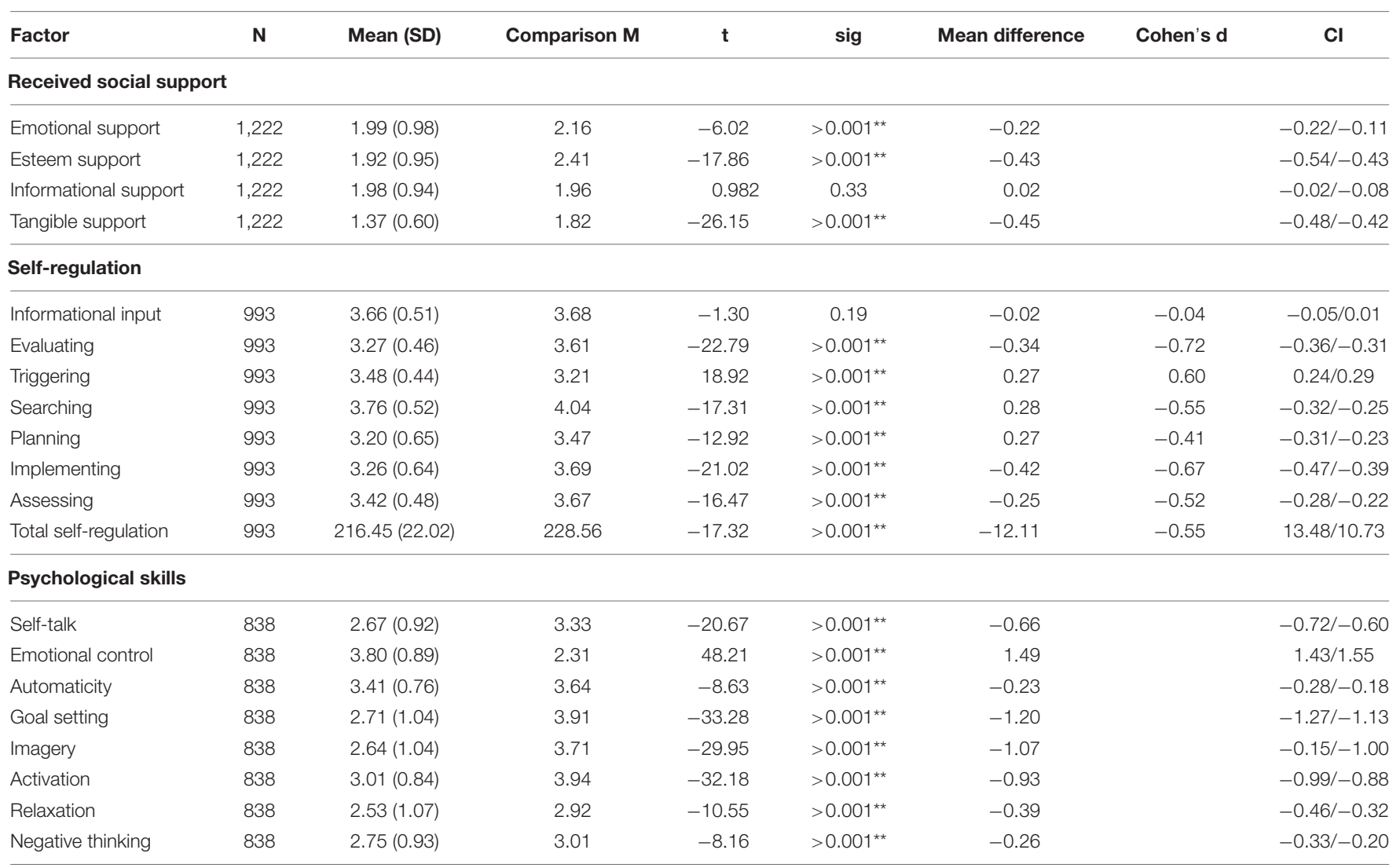

Overall, we compared the findings of the present study with results obtained in a sample of 222 athletes, ranging from recreational to international competition levels in cycling, rugby, and soccer (Hartley and Coffee, 2019; see Table 5). This comparison showed that the e-athletes reported significantly lower levels of esteem, emotional and tangible support, but similar levels of informational support. For self-regulation, e-athletes scored significantly lower for evaluating, searching, 
planning, implementing, assessing, and total self-regulation, but higher for triggering. Finally, for psychological skill use, e-athletes reported significantly less use of self-talk, automaticity, goal setting, imagery, relaxation, negative thinking and activation, but higher use of emotional control.

The MANOVA exploring the association between player rank and social support was significant (Wilk's lambda $=0.94$, $\left.p<0.001 ; \eta_{p}{ }^{2}=0.02\right)$. Follow up ANOVAs showed significant differences for esteem support $[F(3,1,000)=11.81, p<0.001$; $\left.\eta_{p}{ }^{2}=0.034\right]$, emotional support $[F(3,1,000)=8.80, p<0.001$; $\left.\eta_{p}^{2}=0.03\right]$, informational support $[F(3,1,000)=13.95, p<0.001$; $\left.\eta_{p}^{2}=0.03\right]$, and tangible support $[F(3,1,000)=10.80, p<0.001$; $\left.\eta_{p}{ }^{2}=0.031\right]$ all with a small effect size. Post hoc comparisons showed that the top $10 \%$ skill group of e-athletes received more emotional and information support than those ranked $79 \%$ or below, and more esteem support than those ranked in the bottom $69 \%$. Similarly, those ranked $80-89 \%$ received more esteem and informational support than those ranked $69 \%$ or below.

The MANOVA for self-regulation and player rank was significant (Wilk's lambda $=0.94, p<0.001 ; \eta_{p}{ }^{2}=0.21$ ). Follow up ANOVAs showed significant differences for input $[F(3$, $\left.818)=5.45, p=0.001 ; \eta_{p}^{2}=0.02\right]$, triggering $[F(3,818)=2.69$, $\left.p=0.045 ; \eta_{p}{ }^{2}=0.01\right]$, searching $[F(3,818)=5.85 p=0.001$; $\left.\eta_{p}{ }^{2}=0.02\right]$, planning $\left[F(3,818)=4.22, p=0.01 ; \eta_{p}{ }^{2}=0.02\right]$, and assessing $\left[F(3,818)=3.33, p=0.02 ; \eta_{p}^{2}=0.012\right]$ all with a small effect size. No significant differences were found for evaluating $\left[F(3,818)=0.47, p=0.09 ; \eta_{p}^{2}=0.01\right]$ or implementing $[F(3$, $\left.818)=0.84, p=0.10 ; \eta_{p}^{2}=0.01\right]$. Post hoc comparisons showed that the top $10 \%$ skill group of e-athletes reported significantly higher scores for informational input, searching, planning, and assessing behaviour than the 0-69\% group and, for searching, higher than the $80-89 \%$ group. No significant differences were found for triggering.

The MANOVA for psychological skill use and player rank was significant (Wilk's lambda $=0.89, p<0.001 ; \eta_{p}^{2}=0.37$ ). Follow up ANOVAs showed significant differences for self-talk $[F(3$, $\left.697)=4.76, p=0.003 ; \eta_{p}^{2}=0.02\right]$, automaticity $[F(3,697)=14.90$, $\left.p<0.001 ; \eta_{p}{ }^{2}=0.06\right]$, goal-setting $[F(3,697)=6.73, p<0.001$; $\left.\eta_{p}{ }^{2}=0.03\right]$, imagery $\left[F(3,679)=6.80, p<0.001 ; \eta_{p}{ }^{2}=0.03\right]$, and activation $\left[F(3,679)=8.50, p<0.001 ; \eta_{p}{ }^{2}=0.04\right]$ all with a small effect size except for automaticity which had a medium effect size. No significant differences were found for emotional control $[F(3$, $\left.696)=0.75, p=0.75 ; \eta_{p}^{2}=0.003\right]$, relaxation $[F(3,696)=0.76$, $\left.p=0.52 ; \eta_{p}^{2}=0.003\right]$, or negative thinking $[F(3,696)=0.76$, $\left.p=0.39 ; \eta_{p}^{2}=0.004\right]$. Post hoc comparisons showed that the e-athletes in the top $10 \%$ skill group scored significantly higher on positive self-talk and automaticity, compared to the $0-69 \%$ skill group, and imagery and activation with all other skill groups. For automaticity, the 0-69\% skill group scored significantly lower than all other skill groups.

\section{DISCUSSION}

This study examined the level of social support, self-regulation and psychological skill use in e-athletes in comparison to traditional athletes and how this was associated by in game rank (achievement level). Findings showed that e-athletes received less social support, reported less self-regulation and generally had a lower level of psychological skill use compared to traditional athletes. However, this was influenced by skill level with those in the top $10 \%$ reporting higher levels of social support, selfregulation and some psychological skill use.

In this study, e-athletes reported less received social support than traditional athletes. Specifically, e-athletes received less esteem, emotional, and tangible social support, but similar levels of informational social support, compared to traditional athletes. The similar levels of received support, compared to traditional athletes, may indicate that informational support is one of the most influential forms of received social support in esports, and thus e-athletes report its use more frequently. Previous research has suggested that informational support and tangible support are the foundations for esteem and emotional support in an esports context. Specifically, Freeman and Wohn (2017) suggested that most e-athletes started out as strangers and that in-game acts of helping were in the form of informational and tangible support. One way that informational support can manifest is in the form of in-game "pings," which provide e-athletes with a quick targeted method of communication to increase situational awareness (Leavitt et al., 2016). As e-athletes begin to compete together more regularly, and their relationships become more complex, informational and tangible support lead to more emotional and esteem support (Freeman and Wohn, 2017). Despite the potential for functional social support to be developed through in-game relationships, other avenues for support, such as through a coach, are less likely in esports, compared to traditional sports, due to the lower number of esports developmental or grassroots programs. In traditional sport, social support has been associated with improved performance (Rees and Freeman, 2007; Freeman et al., 2009) and well-being (Holt and Hoar, 2006). It would be important to explore how e-athletes reporting lower levels of social support can enhance their levels of received functional social support. Hence, increasing levels of received functional social support could be beneficial by acting as stress-buffering (Rees and Freeman, 2007).

In this study, it was found that e-athletes had lowto-moderate levels of self-regulation and significantly lower total scores of self-regulation when compared to traditional athletes. Additionally, e-athletes also reported significantly lower self-regulatory scores for evaluation, searching, planning, implementing, and assessing factors compared to traditional athletes. However, they had higher scores for triggering. It is theorised that the lower scores of self-regulation in e-athletes stems from the lack of access to esports coaching. Selfregulation has been shown to be developed through the coregulation of self-regulatory skills by coaches and parents (Collins and Durand-Bush, 2014). The low-to-moderate levels of self-reported self-regulation by e-athletes, and significantly lower levels of self-regulation compared to traditional athletes, might be explained by the lower number of developmental and grassroots esports programs compared to traditional sport. As esports developmental and grassroots programs are not as common as traditional sports programs, there may not be as much opportunity for e-athletes to be exposed to relationships who could co-regulate and develop selfregulatory skills. 
Triggering refers to conscious use of internal or external cues to correct behaviour which is not working. Esports have set parameters or rules. E-athletes are likely to get attuned to the rules, constantly scanning for information to make changes to gain an advantage or maintain dominance over their opponents. As esports is played in the digital world these cues are likely to be more consistent and recognisable compared to the physical world. As such triggering might be developed more in e-athletes compared to traditional athletes.

Finally, all self-reported psychological skills used by e-athletes differed significantly from the psychological skill use reported by traditional athletes. Results indicated that e-athletes reported significantly less use of self-talk, automaticity, goal setting, imagery, activation, relaxation, and negative thinking than swimmers (Kruk et al., 2017). However, e-athletes reported significantly greater use of emotional control. Previous, qualitative research, with a small elite sample of League of Legends athletes, has shown that they reported the use of goal setting, flow (automaticity), and emotional self-regulation to enhance their performance (Himmelstein et al., 2017; Poulus et al., in press). Previous research suggests that PST programs for traditional athletes are effective for increasing athlete psychological, behavioural and performance outcomes (Barker et al., 2020). It is likely that most of the e-athletes in the present study have not been exposed to strategies to develop their psychological skills (e.g., through coaching or psychological support), despite previous research indicating that e-athletes would benefit from such training (Himmelstein et al., 2017).

Interestingly, emotional control was found to be higher in e-athletes compared to traditional sports athletes but did not vary based on player rank. It is possible that emotional control is used more by e-athletes than the comparison group of traditional sports, due to the high level of anti-social behaviour reported by e-athletes. Poulus et al. (in press) reported that anti-social behaviour was the highest reported, second-order stressor and represents a significant source of stress for competitive e-athletes. It is possible that exposure to anti-social behaviour in esports games has led to development of increased emotional control as a coping mechanism across all e-athletes. Further research is required to better understand how emotional control is developed and used by e-athletes.

Considering the notion that higher levels of received social support have been associated with increased performance (Rees and Freeman, 2007; Freeman et al., 2009), it is not surprising that the e-athletes ranked in the top $10 \%$ reported higher levels of social support across the four factors assessed. The crosssectional nature of the study does not allow us to say whether increased social support resulted in higher ranking or vice versa. However, the notion that social support is considered to be important for the well-being of athletes (e.g., Rees and Hardy, 2000) suggests that future research could examine whether this is the case for e-athletes. Secondly, it would be important to examine whether higher levels of received social support are related to the different organisational structures in esports. As indicated, higher ranked e-athletes are more likely to play in established teams with coaches and/or other support staff providing greater opportunities for social support, compared to those who compete online alone.
As indicated, previously, self-regulatory skills have been shown to be related to higher levels of sport performance (e.g., Jonker et al., 2011). Importantly, all of the stages of the cyclical process of self-regulation, as defined by Zimmerman (2000), have been associated with increased performance in traditional sports (Toering et al., 2009; Jonker et al., 2010; Popa et al., 2020). The results from this study indicate that, just as in traditional sports, being ranked higher as an e-athlete was associated with more refined self-regulatory skills. In particular, skills associated with forethought and self-reflection phases of self-regulation were significantly associated with higher rank in e-athletes. This finding is likely because e-athletes, who invest time to increase their skills by selecting strategies and goals directed at increasing their skills, and then reflect on the effectiveness of those strategies and goals, are more likely to increase their performance.

Higher player rank was also associated with greater use of the following psychological skills: self-talk, automaticity, imagery, and activation. These psychological skills have been associated with higher levels of sports performance (e.g., Cheng et al., 2015; Arthur et al., 2017; Simonsmeier and Buecker, 2017). Importantly, self-talk, goal setting, and imagery are also associated with Zimmerman's (2000) cyclical theory of selfregulation. As such, the higher levels of self-regulation reported by the top $10 \%$ of e-athletes might be partially due to greater use of some psychological skills.

Despite the generally low scores, the positive and significant relationships social support, self-regulation, and psychological skill use have with esports player rank is encouraging. In particular, because these factors can be developed e-athletes wishing to increase their ranking may seek out opportunities to take part in developmental programs targeting these aspects of esports high performance.

Despite best efforts, this study has some limitations. Firstly, participant responses could have been impacted by the self-report measures used. For example, it is possible that participants may have answered the surveys in a way they believed was socially desirable. Second, this study was only distributed in English, which may have impacted the number of participants who were able to take part from non-English speaking countries. Thirdly, the study was cross-sectional in nature which only allows for associations and not causation. Fourth, the e-athletes in this study competed in MOBA esports. The traditional athletes in the comparison studies for social support and psychological skill use competed in diverse but mainly team sports. However, for selfregulation the comparison sample consisted of swimmers. To date it is unclear whether participating in a team or individual sport result in varied development of self-regulatory skills. A final limitation of this study is the single cohort nature of the comparison between e-athletes and traditional athletes. In support of previous research (Himmelstein et al., 2017; Brevers et al., 2020), we also recommend that future studies investigate interventions focused on the development of social support, self-regulation, and psychological skill development through developmental esports programs, such as youth grassroots esports competitions in high-schools or the general community. Future research could also investigate the longterm effects of developmental and grassroots esports programs and competitions. 
The present study's findings highlight that social support, self-regulation, and the use of psychological skills in e-athletes are generally lower than those observed in traditional sporting populations. Further, it is noted that social support, self-regulation, and psychological skill use are significantly and positively related to esports player rank. In summary, developmental esports programs may have the potential to promote effective and generalisable self-regulation skills. In comparison with traditional sport development programs, social support (e.g., coaches, parents) is an underused resource that can potentially foster the co-regulation of psychological skill use to increase in-game performance and future life outcomes.

\section{DATA AVAILABILITY STATEMENT}

The raw data supporting the conclusions of this article will be made available by the authors, without undue reservation.

\section{REFERENCES}

Ahn, J., Collis, W., and Jenny, S. (2020). The one billion dollar myth: methods for sizing the massively undervalued esports revenue landscape. Int. J. Esports 1. Available online at: https://www.ijesports.org/article/15/html

Arnold, R., Edwards, T., and Rees, T. (2018). Organizational stressors, social support, and implications for subjective performance in high-level sport. Psychol. Sport Exerc. 39, 204-212. doi: 10.1016/j.psychsport.2018.08.010

Arthur, R. A., Fitzwater, J., Roberts, R., Hardy, J., and Arthur, C. A. (2017). Psychological Skills and "the Paras": the Indirect Effects of Psychological Skills on Endurance. J. Appl. Sport Psychol. 29, 449-465. doi: 10.1080/10413200.2017. 1306728

Barker, J. B., Slater, M. J., Pugh, G., Mellalieu, S. D., McCarthy, P. J., Jones, M. V., et al. (2020). The effectiveness of psychological skills training and behavioral interventions in sport using single-case designs: a meta regression analysis of the peer-reviewed studies. Psychol. Sport Exerc. 51:101746. doi: 10.1016/j. psychsport.2020.101746

Bartulovic, D., Young, B. W., and Baker, J. (2017). Self-regulated learning predicts skill group differences in developing athletes. Psychol. Sport Exerc. 31, 61-69. doi: 10.1016/j.psychsport.2017.04.006

Brevers, D., King, D. L., and Billieux, J. (2020). Delineating adaptive esports involvement from maladaptive gaming: a self-regulation perspective. Curr. Opin. Psychol. 36, 141-146. doi: 10.1016/j.copsyc.2020.07.025

Brown, D. J., and Fletcher, D. (2017). Effects of Psychological and Psychosocial Interventions on Sport Performance: a Meta-Analysis. Sports Med. 47, 77-99. doi: 10.1007/s40279-016-0552-7

Brown, J. M. (1998). "Self-Regulation and the Addictive Behaviors," in Treating Addictive Behaviors, eds W. R. Miller and N. Heather (New York, NY: Plenum Press), 61-73.

Brown, J. M., Miller, W. R., and Lawendowski, L. A. (1999). "The Self-regulation Questionnaire (SRQ)," in Innovations in Clinical Practice: A Source Book, eds L. VandeCreek and T. L. Jackson (Sarasota, FL: Professional Resource Press), 281-292.

Cheng, M.-Y., Huang, C.-J., Chang, Y.-K., Koester, D., Schack, T., and Hung, T.-M. (2015). Sensorimotor Rhythm Neurofeedback Enhances Golf Putting Performance. J. Sport Exerc. Psychol. 37, 626-636. doi: 10.1123/jsep.2015-0166

Cohen, J. (1988). Statistical Power Analysis for the Behavioral Sciences, 2nd Edn. Hillsdale, NJ: Lawrence Erlbaum Associates.

Collins, J., and Durand-Bush, N. (2014). Strategies Used by an Elite Curling Coach to Nurture Athletes' Self-Regulation: a Single Case Study. J. Appl. Sport Psychol. 26, 211-224. doi: 10.1080/10413200.2013.819823

DeFreese, J. D., and Smith, A. L. (2013). Teammate social support, burnout, and self-determined motivation in collegiate athletes. Psychol. Sport Exerc. 14, 258-265. doi: 10.1016/j.psychsport.2012.10.009

\section{ETHICS STATEMENT}

The studies involving human participants were reviewed and approved by the Queensland University of Technology - Office of Research Ethics and Integrity, Research Ethics Advisory Team. The patients/participants provided their written informed consent to participate in this study.

\section{AUTHOR CONTRIBUTIONS}

MT and RP: conceptualisation, formal analysis, data curation, and project administration. MT, RP, and DP: methodology and investigation. RP: resources. MT: writing-original draft preparation. MT, TC, PD, DP, and RP: writingreview and editing. TC, PD, and RP: supervision. All authors have read and agreed to the published version of the manuscript.

Erikstad, M. K., Høigaard, R., Johansen, B. T., Kandala, N.-B., and Haugen, T. (2018). Childhood football play and practice in relation to self-regulation and national team selection; a study of Norwegian elite youth players. J. Sports Sci. 36, 2304-2310. doi: 10.1080/02640414.2018.1449563

Fitzwater, J. P. J., Arthur, C. A., and Hardy, L. (2018). “The tough get tougher”: mental skills training with elite military recruits. Sport Exerc. Perform. Psychol. 7, 93-107. doi: 10.1037/spy0000101

Freeman, G., and Wohn, D. Y. (2017). "Social Support in eSports: building Emotional and Esteem Support from Instrumental Support Interactions in a Highly Competitive Environment," in CHI PLAY 2017 - Proceedings of the Annual Symposium on Computer-Human Interaction in Play (Amsterdam: Association for Computing Machinery), 435-447. doi: 10.1145/3116595. 3116635

Freeman, G., and Wohn, D. Y. (2019). Understanding eSports Team Formation and Coordination. Comput. Support. Coop. Work 28, 95-126. doi: 10.1007/ s10606-017-9299-4

Freeman, P. (2020). "Social Support in Sport," in Handbook of Sport Psychology (1st ed), eds G. Tenenbaum and R. C. Eklund (Hoboken: Wiley), 447-463. doi: 10.1002/9781119568124.ch21

Freeman, P., Coffee, P., Moll, T., Rees, T., and Sammy, N. (2014). The ARSQ: the Athletes' Received Support Questionnaire. J. Sport Exerc. Psychol. 36, 189-202. doi: 10.1123/jsep.2013-0080

Freeman, P., Coffee, P., and Rees, T. (2011). The PASS-Q: the Perceived Available Support in Sport Questionnaire. J. Sport Exerc. Psychol. 33, 54-74. doi: 10.1123/ jsep.33.1.54

Freeman, P., and Rees, T. (2008). The effects of perceived and received support on objective performance outcome. Eur. J. Sport Sci. 8, 359-368. doi: 10.1080/ 17461390802261439

Freeman, P., and Rees, T. (2010). Perceived social support from team-mates: direct and stress-buffering effects on self-confidence. Eur. J. Sport Sci. 10, 59-67. doi: 10.1080/17461390903049998

Freeman, P., Rees, T., and Hardy, L. (2009). An Intervention to Increase Social Support and Improve Performance. J. Appl. Sport Psychol. 21, 186-200. doi: $10.1080 / 10413200902785829$

Ghasemi, A., and Zahediasl, S. (2012). Normality Tests for Statistical Analysis: a Guide for Non-Statisticians. Int. J. Endocrinol. Metab. 10, 486-489. doi: 10. 5812/ijem.3505

Gupta, S., and Sudhesh, N. (2019). Grit, self-regulation and resilience among college football players: a pilot study. Int. J. Physiol. Nutr. Phys. Educ. 4, 843-848.

Hardy, L., Roberts, R., Thomas, P. R., and Murphy, S. M. (2010). Test of Performance Strategies (TOPS): instrument refinement using confirmatory factor analysis. Psychol. Sport Exerc. 11, 27-35. doi: 10.1016/j.psychsport.2009. 04.007 
Hartley, C., and Coffee, P. (2019). Perceived and Received Dimensional Support: main and Stress-Buffering Effects on Dimensions of Burnout. Front. Psychol. 10:1724. doi: 10.3389/fpsyg.2019.01724

Himmelstein, D., Liu, Y., and Shapiro, J. L. (2017). An Exploration of Mental Skills Among Competitive League of Legend Players. Int. J. Gaming Comput. Mediat. Simul. 9, 1-21. doi: 10.4018/IJGCMS.2017040101

Holt, N. L., and Hoar, S. D. (2006). "The Multidimensional Construct of Social Support," in Literature Review in Sport Psychology, eds S. Hanton and S. D. Mellalieu (Hauppauge, New York, NY: Nova Science Publishers).

Jenny, S. E., Manning, R. D., Keiper, M. C., and Olrich, T. W. (2017). Virtual (ly) athletes: where eSports fit within the definition of "Sport". Quest 69, 1-18. doi: 10.1080/00336297.2016.1144517

Jonker, L., Elferink-Gemser, M. T., and Visscher, C. (2010). Differences in selfregulatory skills among talented athletes: the significance of competitive level and type of sport. J. Sports Sci. 28, 901-908. doi: 10.1080/02640411003797157

Jonker, L., Elferink-Gemser, M. T., and Visscher, C. (2011). The role of selfregulatory skills in sport and academic performances of elite youth athletes. Talent Dev. Excell. 3, 263-275.

Kang, J. O., Kang, K. D., Lee, J. W., Nam, J. J., and Han, D. H. (2020). Comparison of Psychological and Cognitive Characteristics between Professional Internet Game Players and Professional Baseball Players. Int. J. Environ. Res. Public Health 17:4797. doi: 10.3390/ijerph17134797

Kruk, M., Blecharz, J., Boberska, M., Zarychta, K., and Luszczynska, A. (2017). Mental Strategies Predict Performance and Satisfaction with Performance Among Soccer Players. J. Hum. Kinet. 59, 79-90. doi: 10.1515/hukin2017-0149

Leavitt, A., Keegan, B. C., and Clark, J. (2016). "Ping to Win?: Non-Verbal Communication and Team Performance in Competitive Online Multiplayer Games," in Proceedings of the 2016 CHI Conference on Human Factors in Computing Systems (New York, NY: ACM), 4337-4350. doi: 10.1145/2858036. 2858132

López-Cabarcos, M. Á, Ribeiro-Soriano, D., and Piñeiro-Chousa, J. (2020). All that glitters is not gold. The rise of gaming in the COVID-19 pandemic. J. Innov. Knowl. 5, 289-296. doi: 10.1016/j.jik.2020.10.004

Meggs, J., and Chen, M. A. (2019). Competitive Performance Effects of Psychological Skill Training for Youth Swimmers. Percept. Mot. Skills 126, 886-903. doi: 10.1177/0031512519852533

Newzoo (2020). Newzoo Global Esports Market Report 2020 | Light Version. Available online at: https://newzoo.com/insights/trend-reports/newzooglobal-esports-market-report-2020-light-version/ (accessed May 2, 2020).

Pilgrim, J., Kremer, P., and Robertson, S. (2018). The self-regulatory and taskspecific strategies of elite-level amateur golfers in tournament preparation. Sport Psychol. 32, 169-177. doi: 10.1123/tsp.2017-0056

Polman, R., Trotter, M., Poulus, D., and Borkoles, E. (2018). "eSport: Friend or Foe?," in Serious Games, eds S. Göbel, A. Garcia-Agundez, T. Tregel, M. Ma, J. Baalsrud Hauge, M. Oliveira, et al. (Basel, Switzerland: Springer International Publishing), 3-8. doi: 10.1007/978-3-030-02762-9_1

Popa, D., Mîndrescu, V., Iconomescu, T.-M., and Talaghir, L.-G. (2020). Mindfulness and self-regulation strategies predict performance of romanian handball players. Sustainability 12:3667. doi: 10.3390/su120 93667

Poulus, D., Coulter, T. J., Trotter, M. G., and Polman, R. (2020). Stress and Coping in Esports and the Influence of Mental Toughness. Front. Psychol. 11:628. doi: $10.3389 /$ fpsyg.2020.00628

Poulus, D. R., Coulter, T. J., Trotter, M. G., and Polman, R. (in press). Perceived stressors experienced by competitive esports athletes. Int. J. Esports.

Rees, T., and Freeman, P. (2007). The effects of perceived and received support on self-confidence. J. Sports Sci. 25, 1057-1065. doi: 10.1080/026404106009 82279

Rees, T., and Hardy, L. (2000). An Investigation of the Social Support Experiences of High-Level Sports Performers. Sport Psychol. 14, 327-347. doi: 10.1123/tsp. 14.4.327
Rees, T., Ingledew, D. K., and Hardy, L. (1999). Social support dimensions and components of performance in tennis. J. Sports Sci. 17, 421-429. doi: 10.1080/ 026404199365948

Röthlin, P., Horvath, S., Trösch, S., Holtforth, M. G., and Birrer, D. (2020). Differential and shared effects of psychological skills training and mindfulness training on performance-relevant psychological factors in sport: a randomized controlled trial. BMC Psychol. 8:80. doi: 10.1186/s40359-020-00449-7

Sadri, A., and Janani, H. (2015). Relationship of Emotional Intelligence and Selfregulation of Male Elite Swimmers. Ann. Appl. Sport Sci. 3, 9-18. doi: 10.18869/ acadpub.aassjournal.3.4.9

Shaari, J. S., Hooi, L. B., and Siswantoyo, S. (2019). The effectiveness of psychological skills training program on netball shooting performance. Jurnal Cakrawala Pendidikan 38, 174-187. doi: 10.21831/cp.v38i1.23206

Shandi, M., Ardekani, Z. P., and Mehri, S. (2016). Comparison of Self-Regulation Strategies in Elite Basketball Players Based on Personality Types. Am. J. Sports Sci. 4:18. doi: 10.11648/j.ajss.20160402.11

Simonsmeier, B. A., and Buecker, S. (2017). Interrelations of Imagery Use, Imagery Ability, and Performance in Young Athletes. J. Appl. Sport Psychol. 29, 32-43. doi: 10.1080/10413200.2016.1187686

Smith, M. J., Birch, P. D. J., and Bright, D. (2019). Identifying Stressors and Coping Strategies of Elite Esports Competitors. Int. J. Gaming Comput. Mediat. Simul. 11, 22-39. doi: 10.4018/IJGCMS.2019040102

Te Wierike, S. C. M., Huijgen, B. C. H., Jonker, L., Elferink-Gemser, M. T., and Visscher, C. (2018). The importance and development of ball control and (self-reported) self-regulatory skills in basketball players for different positions. J. Sports Sci. 36, 710-716. doi: 10.1080/02640414.2017.1334954

Thapar, D. R., and Nancy, N. (2018). Investigating grit among para sportspersons in relation to self- regulation and motivation factors. Univ. Rev. 7, 1261-1271.

Tod, D., Hardy, J., and Oliver, E. (2011). Effects of Self-Talk: a Systematic Review. J. Sport Exerc. Psychol. 33, 666-687. doi: 10.1123/jsep.33.5.666

Toering, T. T., Elferink-Gemser, M. T., Jordet, G., and Visscher, C. (2009). Selfregulation and performance level of elite and non-elite youth soccer players. J. Sports Sci. 27, 1509-1517. doi: 10.1080/02640410903369919

Trotter, M. G., Coulter, T. J., Davis, P. A., Poulus, D. R., and Polman, R. (2020). The Association between Esports Participation, Health and Physical Activity Behaviour. Int. J. Environ. Res. Public Health 17:7329. doi: 10.3390/ ijerph17197329

Woodman, T., Zourbanos, N., Hardy, L., Beattie, S., and McQuillan, A. (2010). Do performance strategies moderate the relationship between personality and training behaviors? an exploratory study. J. Appl. Sport Psychol. 22, 183-197. doi: 10.1080/10413201003664673

Zimmerman, B. J. (2000). “Attaining Self-Regulation,” in Handbook of SelfRegulation, eds M. Boekaerts, P. R. Pintrich, and M. Zeidner (Cambridge, M: Academic Press), 13-39. doi: 10.1016/B978-012109890-2/50031-7

Conflict of Interest: The authors declare that the research was conducted in the absence of any commercial or financial relationships that could be construed as a potential conflict of interest.

Publisher's Note: All claims expressed in this article are solely those of the authors and do not necessarily represent those of their affiliated organizations, or those of the publisher, the editors and the reviewers. Any product that may be evaluated in this article, or claim that may be made by its manufacturer, is not guaranteed or endorsed by the publisher.

Copyright (c) 2021 Trotter, Coulter, Davis, Poulus and Polman. This is an open-access article distributed under the terms of the Creative Commons Attribution License (CC BY). The use, distribution or reproduction in other forums is permitted, provided the original author(s) and the copyright owner(s) are credited and that the original publication in this journal is cited, in accordance with accepted academic practice. No use, distribution or reproduction is permitted which does not comply with these terms. 